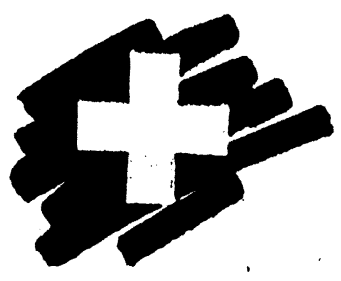

\title{
MEDECINS SANS FRONTIERES
}

68, bd St-Marcel 75005 Paris - France. Tél. : (I) 47.07.29.29

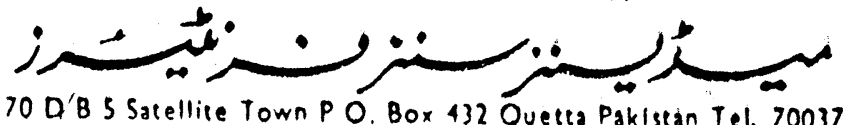

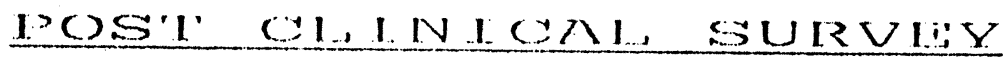

$-$

OF AN IODIZED OIL INUECIION PHOJEOT

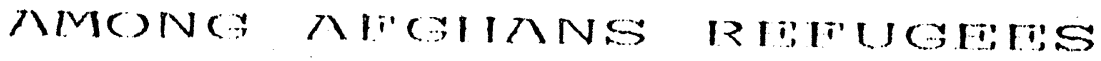

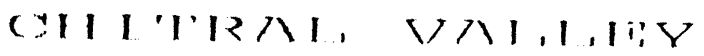

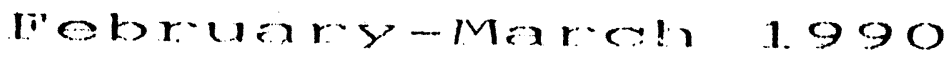

Christine Bousquet, RN . 


\section{CON'TENIS:}

$I$ : INIROIOUCIICON

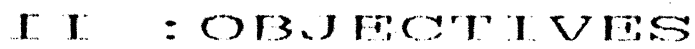

III : ME'INOLOI,OGY

I.V : RISGII.IS

$V=$ COMMEINTS

$V I: \quad O O N C: I, L S S I O N$ 
After an lodized ofl injoction was conducted in chltral valley from May 1989 to De.cember 1989. MSF was interested in making an evalua-tion of the project, though a post clinical survey is not fully accu-rate in determining the decrease in goiter stages.

on the other end, 11 , was logistically impossible to study the effects of the injection on urimary iodine.

\section{II: O OBJE:CTIVES:}

The principal aims of this post clinical survey were :

- to determine the coverage of the larget population.

: to appreciate the consumption of iodized salt afler the education campaign we conducted.

- to evaluate the degree of reduction in goller stages.

\section{III: ME'IHODOLOGY :}

Ho previous post a inical survey mothodologies were avallable to us. After careful consideration, we decided that the most appropriate me-thodology was to follow the who rules for vaccination survey, al-though in order to increase the sample size, we surveyed 210 families rather than 210 children.

Target populaticon : (See map, Annex 1 )

The population affected by this survey was the $\lambda$ fghan refugees 1 iving in the following camps:

- Domshoqur

- Orqush

Shidi

- Bumburet

- Kesu

. Khairabad

- Kalkatak 
Ursum valley and Nagar were covered in December and thus not included in this survey : a minimum of 3 months after the injection is normal- ly requtred to appreclate any change in goiter stages.

\section{AGE AND GROUP EVALUATED :}

The population infected in those camps included :

- male from 0 to 20 years.

- fomalo from o lo 15 years.

30 clusters of 7 families were selected at: random, which made a total of 210 families.

\section{Luster-sampling:}

\section{CUMULATIVE POPULATION: (SEE Annex 2)}

To draw up a list of the cumulative population, we used the popula. -tion figure registered by UNHCR in each camp or in each sub-division. SAMPLING INTERVAL:

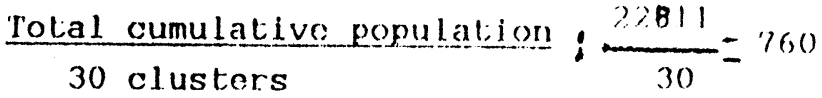

\section{SELECTION OF A RANDOM NUMBER : (See Annex 3)}

The selection of a random number was done with a random table : 372 . Chis number needed to be Ines than or equal to the sampling interval.

Method to determine the houses to be visited withir each clustex:

No list of the houses was available and their irreqular grouping did not allow us to create a house by house map. Therefore, we proceseded in the following way :

- we determined in each sub-division of the camp the number of mosques which would then be the geographic centers of the sub-divi-sion.

- after determination at random of the first mosque, one pencil was thrown into the alr; then, the tip indicated in which direction we had to yo. 
- we drew lots between one and the total number of houses regis-tered in that direction. The survey started with the first house of of the number selected.

There was, however, a small quantity of houses in the sub-division com-pared with the numbers of clusters to do, for this reason, we started with the first house following the direction indicated by the pencll.

Questiorraixe:- (See Annex 1)

We considered that each family was fully covered if all the members between 0 to 2.0 years for male and 0 to 45 years for female had recei-ved the injection and had the reatstration card.

or the refugees who were not able to show us the card, we would check inthe MSF permanent register of the iodized oil injection project.

LV: $:$ RLSUL'IS:

Among the 210 families randomly selected, 180 families had recelved the lodized oil injection, which calculates to 85,7\% of the families.

\begin{tabular}{|c|c|c|c|c|}
\hline $\begin{array}{l}\text { STAGE } \\
\text { GOITER }\end{array}$ & $\begin{array}{l}\text { NUMBER OF } \\
\text { GOITERS CHECKED }\end{array}$ & $\begin{array}{l}\text { NUMIBFR OF GOITERS } \\
\text { WHICH DFCREASFS }\end{array}$ & or & DECRFASFE \\
\hline$x$ & 100 & $\geq 1$ & & $2,1 \quad 9 / 5$ \\
\hline $\mathbf{I} \mathbf{I}$ & 36 & $2: 1$ & & $583,3 \%$ \\
\hline I. 1 & 10 & $?$ & & 20 \\
\hline
\end{tabular}

The number of familles who were using iodized salt was 28 , which calcu. lates to 13,3\% of the famllies sejectied. 
Amongthodio famllies or 956 people visited, of those previously de-termined to have goiters, only 12 individuals were absent during this survey.

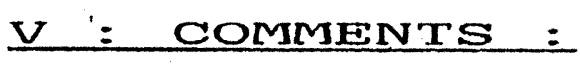

- The majority of defaulters were found in Domshogur : the cluster si-ze here was 32 families of which 8 had missed the injection. Due to a strong "purdah" system, some families did not wish to mix with others during the injection period.

- Goiters decrease : we observed a predominance of goilers in stage 1. We noticed the most significant ratie of decrease was for golters stage 2 but it is possible that the number of stage 2 goiters checked were insufficient to be statistically reliable enough to draw any firm conclusions.

- Among the 180 fornilies fully covered, all had the reqistration card. They kept it carefully inside the plastic cover.

- Despite the provision of daily information about lodized salt which included flip charts and packages of salt, the actual household use is very low. Nevertheloss, the families who have members with visible goiters seem to use it rruplarly.

The connection between uniodized salt and goiter is difficult for the refugee population to make. Behavioural changes regarding the use of Lodzed salt will require intensive and long term education. In the meantime, the inclusion of iodized salt. in rofugee rations is the most effective short term solution to IDD.

\section{VI: $=$ OONOILUSION :}

We noticed that the families took great: interest in and good care of their cards. In the future, these cards can be used ayain in case of subsequent: iodized oil injection project. The registration which took a lona time during the campaian was, in ract, posilive. 
Among the 116 goiters observed, all stages mixed, $32 \%$ had decreased but it is not: olear how these results are to be interpreted.

Although we cannot be certain how reliable our data were, regarding goiter size reduction, we gained a lot of information concerning cove-rage of the target population and use of lodized salt as well as re-qistration cards. 
ANINEX 1 .

MAP (O) CIIISRAL VAI,H:Y.
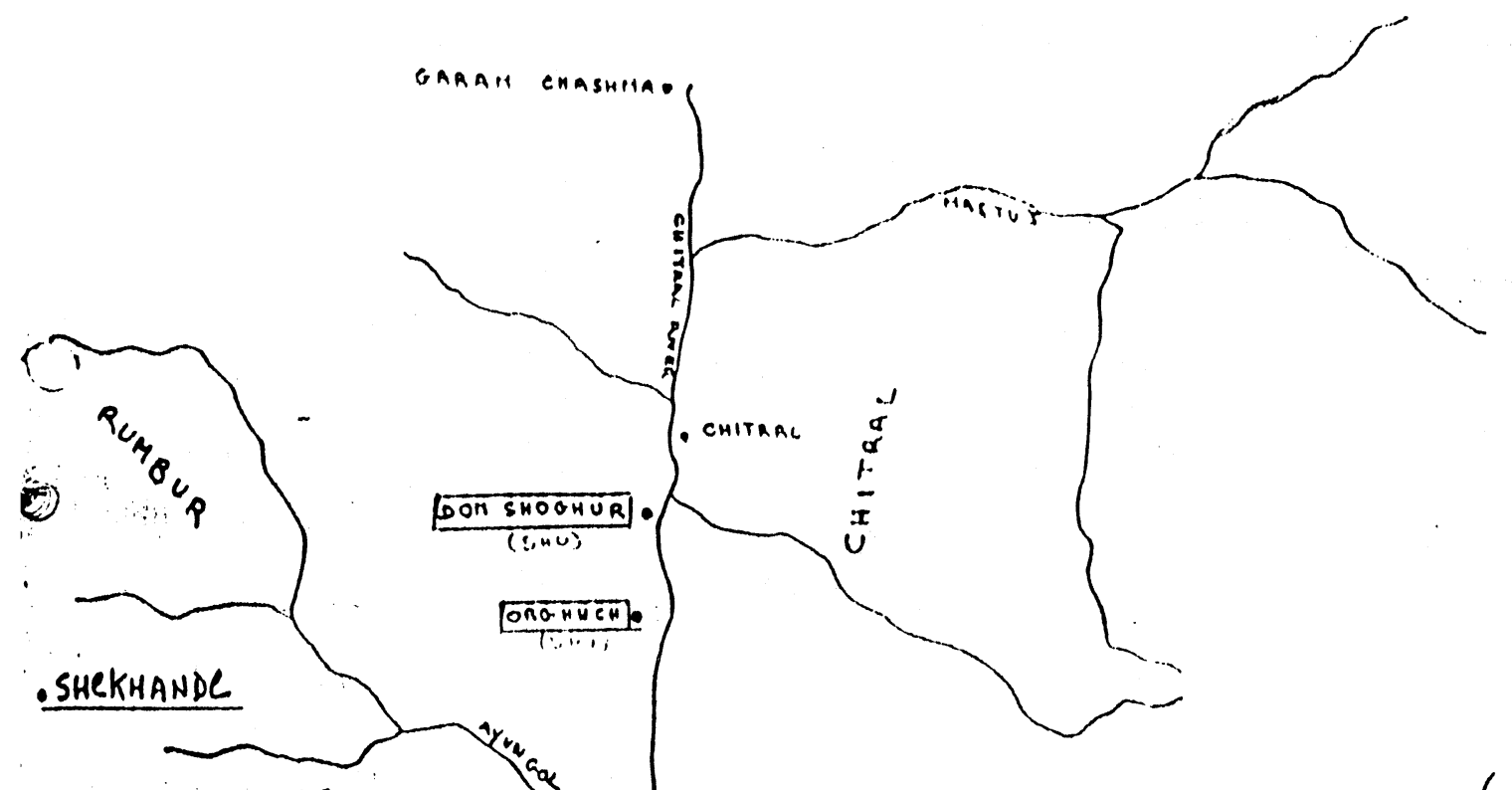

BUNBURET

BIRIR
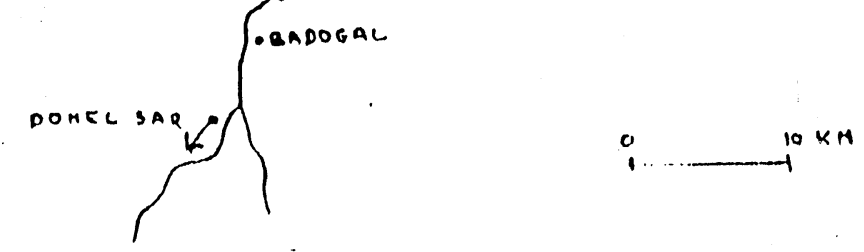


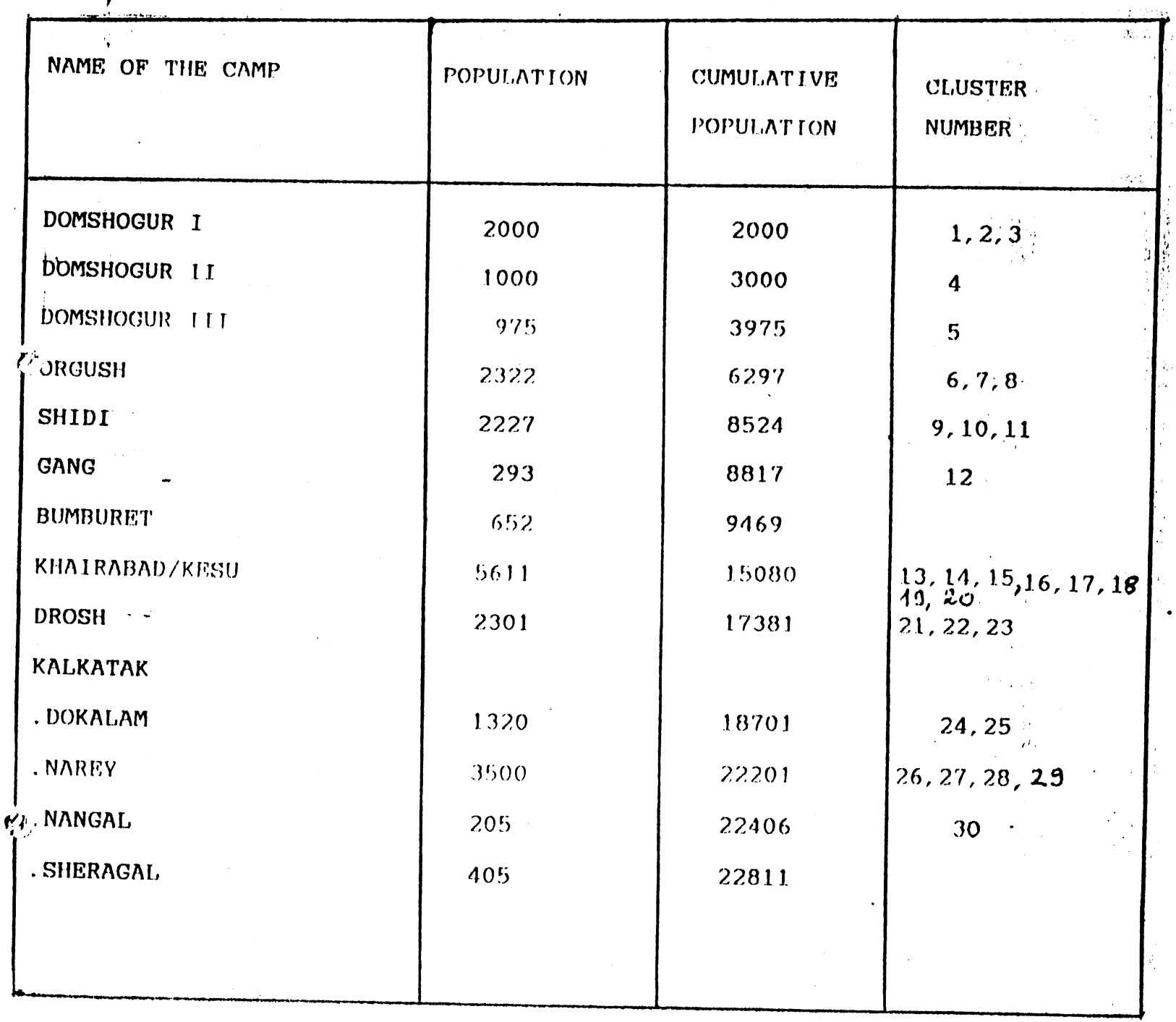


Nombres an hasard

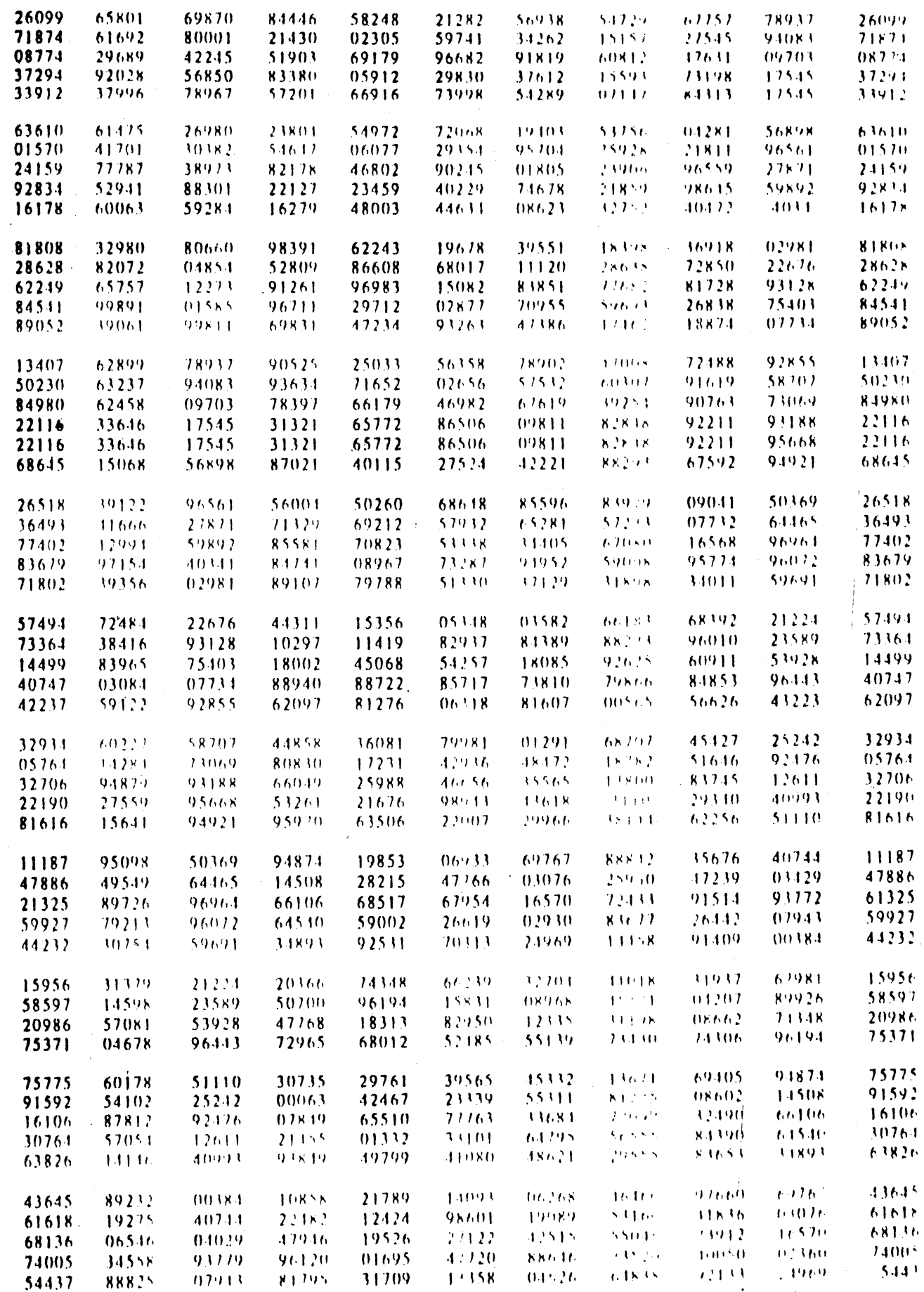




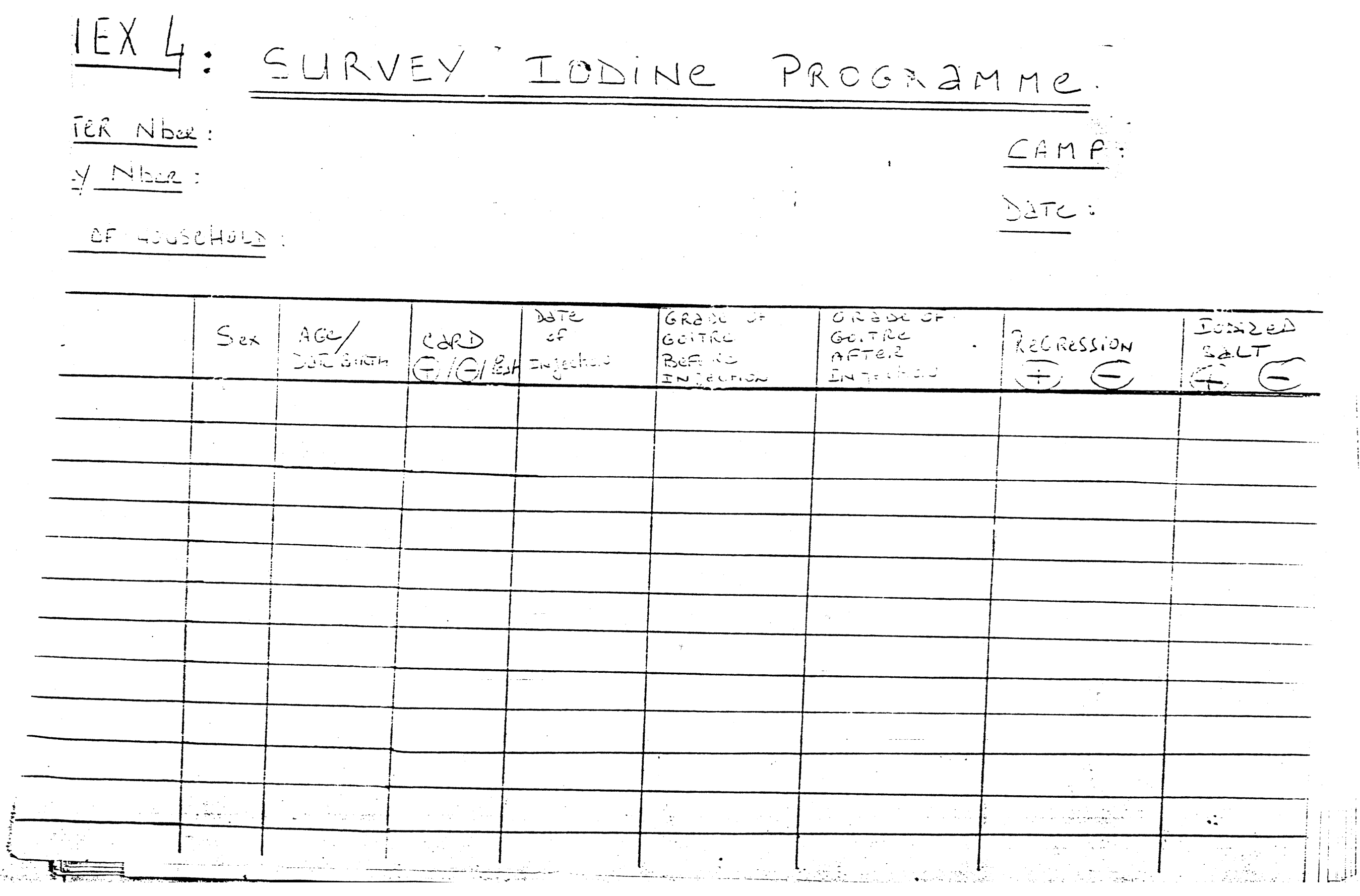

